\title{
Schedule Frequency
}

National Cancer Institute

\section{Source}

National Cancer Institute. Schedule Frequency. NCI Thesaurus. Code C64493.

A regimen for an intervention which consists of a specified number of instances within a specific time period. 